\title{
Aligning Corporate and IT Goals and Strategies in the Oil and Gas Industry
}

\author{
Victor Basili ${ }^{1}$, Constanza Lampasona ${ }^{2}$, and Alexis Eduardo Ocampo Ramírez ${ }^{3}$ \\ ${ }^{1}$ Fraunhofer Center for Experimental Software Engineering, \\ University of Maryland, and King Abdulaziz University \\ College Park, MD, USA \\ basiliafc-ma.umd. edu \\ ${ }^{2}$ Fraunhofer Institute for Experimental Software Engineering \\ Kaiserslautern, Germany \\ constanza. lampasona@iese. fraunhofer.de \\ ${ }^{3}$ ECOPETROL S.A. \\ Bogotá, Colombia \\ alexis.ocampo@ecopetrol.com.co
}

\begin{abstract}
Companies increasingly recognize that IT plays a significant role in their current and future business strategies, and IT departments increasingly need to justify their role in terms of contributions to business goals. Currently, little experience exists on how to effectively create this missing business-IT link. In 2010, ECOPETROL, a global player in the oil and gas industry, launched an initiative to align their IT activities with their overall business goals. IT is becoming a key information provider for making business-oriented decisions and achieving business success. Consequently, the view of IT is from that of a support organization to that of a value-creating information provider. This article describes how ECOPETROL is utilizing IT services to improve their competitiveness in the marketplace. They are applying the $\mathrm{GQM}^{+}$Strategies ${ }^{\circledR}$ approach for measurement-based IT-business alignment.
\end{abstract}

Keywords: D.2.8 Metrics/Measurement, D.2.9 Management.

\section{Introduction}

IT and software are becoming central drivers for innovation and growth for many organizations, and business success increasingly depends on IT and software-related strategies.

In 2010, ECOPETROL, a global player in the oil and gas industry ranked 12 among the top 50 energy companies according to the PIW ranking [6], launched an initiative to better align their IT software development activities with their overall business goals. This changed the role of IT software development from a simple service provider to a central information provider to support decision-making at the highest levels of the organization and thus become a tool for achieving business success. The information orientation [13] concept characterizes the change from classical IT service departments to providers of high-quality information. As a consequence, IT 
software applications have to provide high-quality information. As a result, software development is affected by a lot of implications on how applications should be designed and how they should interact with each other and which architectural patterns should be used in order to enhance information quality and promote effective information usage.

For the implementation of this paradigm shift, it was necessary to link the goals and strategies of the IT department to the overall goals and strategies of ECOPETROL, creating a hierarchy of aligned goals from the top level business goals to the IT project goals making sure that the entire organization is moving in the same direction and demonstrating the value of IT-related activities to the overall organization.

In order to make the goals operational at all levels, it was necessary to establish a measurement system for quantifying the IT contribution and provide a mechanism for monitoring the attainment of goals and the success/failure of the strategies followed.

This article discusses how ECOPETROL is evolving their IT services to improve their competitiveness in the market utilizing the $\mathrm{GQM}^{+}$Strategies ${ }^{\circledR}$ approach. The $\mathrm{GQM}^{+}$Strategies ${ }^{\circledR}$ approach supports companies in aligning IT/software-related strategies with business goals across the entire organization through measurement [2]. It is being applied in several organizations in a variety of domains at various levels of depth. This article will briefly sketch the approach and illustrate how it is being utilized by ECOPETROL for creating an alignment model.

\section{Related Work}

In the past, a variety of approaches have been developed covering different aspects of linking activities related to IT services and software development to the upper-level goals of an organization and demonstrating their business value [4]. The aim of the $\mathrm{GQM}^{+}$Strategies ${ }^{\circledR}$ approach applied in this paper is not meant to replace these approaches, but rather to close the existing gaps with respect to the linking of goals, their implementation, and the measurement data needed to evaluate goal attainment.

The Business Motivation Model [14] (BMM) describes a model and terminology for defining so-called Ends and Means on different levels of an organization. The $\mathrm{GQM}^{+}$Strategies ${ }^{\circledR}$ model follows a similar idea, but explicitly links Ends (called "goals" in the GQM ${ }^{+}$Strategies ${ }^{\circledR}$ terminology) and Means (called "strategies") on multiple levels by specifying rationales for all linkages.

One issue not explicitly addressed by classical software measurement approaches, such as the Goal Question Metric approach [3] (GQM) or Practical Software and Systems Measurement [16] (PSM), is the connection between the data collected and the organizational goals of the company this data contributes to. $\mathrm{GQM}^{+}$Strategies ${ }^{\circledR}$ adds the capability to integrate all measurement data with organization-wide goals and strategies, thus demonstrating the business value generated by the collection of these data. It is based upon the GQM approach, but goes beyond it by making various implicit concepts, such as context and assumptions, explicit and formalizing the concept of a goal hierarchy leading to and derived from strategies. 
When it comes to the higher-level goals of an organization, the Balanced Scorecard [8] (BSC) is a common tool for defining Key Performance Indicators (KPIs). Strategy maps are used to link strategies to corresponding goals and perspectives. However, alignment between different organizational levels and integration of the measurement data are not explicitly addressed. The $\mathrm{GQM}^{+}$Strategies ${ }^{\circledR}$ approach helps establish this link by taking the defined strategy maps and KPIs as input and offering a comprehensive model from the business level down to the project level.

For classical IT services and processes, such as those described by ITIL [15], more elaborate structures addressing business value already exist in the form of an information technology infrastructure library. CoBIT [7] offers an approach for IT governance that addresses multiple organizational levels, but is solely focused on the classical set of IT services. Addressing the change from classical IT service departments to providers of high-quality information requires a more open-ended capability geared to the business goals of the specific organization. GQM ${ }^{+}$Strategies ${ }^{\circledR}$ extends these predefined governance structures and focuses on alignment of the hierarchy of organizational goals. ITIL and CoBIT are basic underlying frameworks for classical IT services and governance, but which do not focus on helping an organization achieve its specific business goals.

\section{GQM $^{+}$Strategies ${ }^{\circledR}$ in a Nutshell}

GQM+Strategies ${ }^{\circledR}$ is an approach for linking operational organizational goals and strategies from the top management level to the project level and back up, aligning the business at all levels of the organization in a seamless way and providing a mechanism for monitoring the success and failure of goals and strategies through measurement. The process consists of (1) generating a grid which represents the hierarchy of operational, strategies, measures and interpretations models, (2) planning and executing the strategies, and (3) analyzing and evaluating the successes and failures of the various strategies with recommendations for improvement. The grid generation phase provides a framework and notation to help organizations develop/package their operational, measureable business goals, select strategies for implementing them, communicate those goals and strategies throughout the organization, and translate those goals into an aligned set of lower-level goals and strategies. The planning and execution phase consists of planning for the implementation of the strategies and executing them as defined. The analysis and evaluation phase helps organizations assess the effectiveness of their strategies at all levels of the organization and recognize the achievement of their business goals over time.

The grid generation activities include learning about the organization and its objectives, specifying the scope of the application, i.e., those parts of the organization that will apply $\mathrm{GQM}^{+}$Strategies ${ }^{\circledR}$, and educating and training the organization in the approach. The output of the planning phase is a detailed and comprehensive model, called the grid, which provides the organization with an aligned set of operational goals and strategies and defines all the elements necessary for a measurement program [2]. The grid allows all parts of the organization to recognize their role in 
achieving the organization's top-level goals, lets them see what is important, how it can be measured, and how those measures will be interpreted. This grid for the organization allows them to make their goals operational, see and achieve consensus on the alignment of the goals, understand what needs to be done to achieve their goals, and realize what measurement needs to take place. Grid generation maybe an end in itself as it clarifies the organization's thinking and can be used in a variety of ways, e.g., providing recognition of what needs to be done, letting the organization select projects that support the organization and eliminate those that do not.

The planning and executing phase and the analysis and evaluation activities involve the use of the measurement program to assess over time the effectiveness of the strategies, the achievement of the goals, and recognition of the need to change both strategies and goals based upon the collection of the prescribed data.

This paper is related with the grid generation phase of $\mathrm{GQM}^{+}$Strategies $^{\circledR}$ at ECOPETROL.

The basic concepts of the approach, represented in the partial grid in Fig. 1, are:

Goals and Strategies

Measurement Data

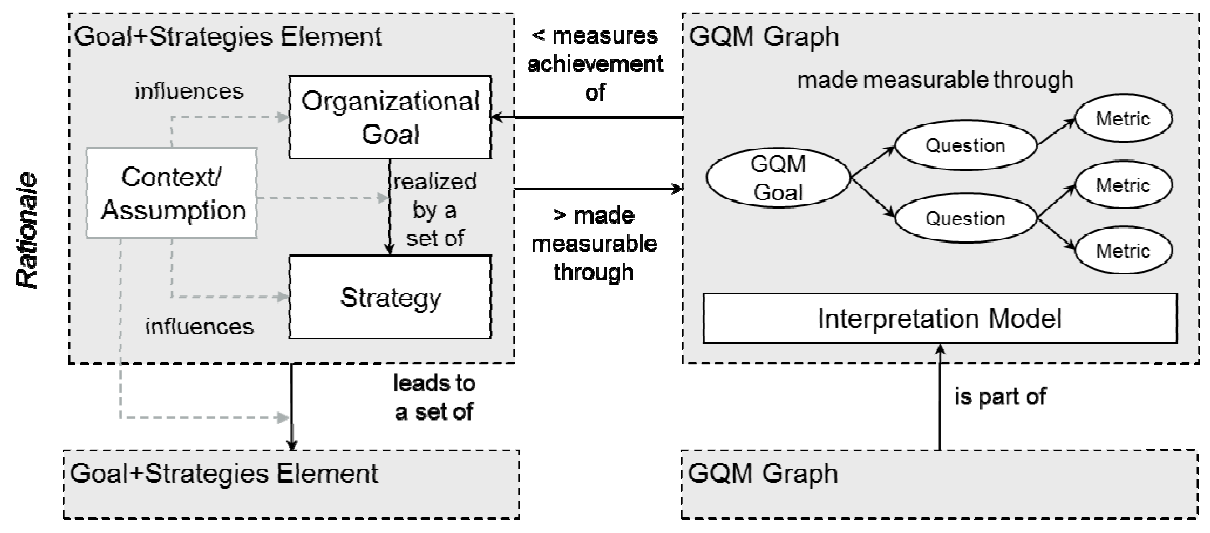

Fig. 1. The GQM ${ }^{+}$Strategies ${ }^{\circledR}$ Model Structure

- Organizational Goals: states that the organization wishes to achieve in order to accomplish its objectives. Their scope can be various parts of the organization (e.g., the management is interested in improved customer satisfaction, or the IT department is interested in reduced rework costs). They define a target state the organization wants to accomplish within a given time frame.

- Strategies: possible approaches for achieving a goal within the environment of the organization. The number of goal/strategy levels depends on the (internal) structure of an organization.

- Context Factors: the external and internal organizational environment, e.g., the business environment, the company's position in the market, or the resources available for innovation. 
- Assumptions: estimated unknowns, i.e., what is believed to be true but needs to be re-evaluated over time. The relevant context factors and assumptions define the rationale for choosing specific goals and strategies.

- GQM Graphs: the definition of how to measure whether a goal was accomplished and whether a strategy was successful. Following the classical GQM approach, GQM goals are defined and broken down into concrete metrics. Interpretation models are used for objectively evaluating goals and strategies.

The entire model provides an organization with a mechanism for not only defining measurement consistent with larger, upper-level organizational concerns, but also for interpreting and rolling up the resulting measurement data at each level. Fig. 2 illustrates the relationship between different organizational units involved in defining a strategic measurement program and the $\mathrm{GQM}^{+}$Strategies ${ }^{\circledR}$ grid. Obtaining a certain goal and applying a certain strategy are the responsibilities of different units in the organization. The grid documents the relationships between the different goals and strategies of the organizational units and explains how to use the collected measurement data for decision making. In the example shown in Fig. 2, six different organizational units are involved in defining the grid. Overall, one business unit goal and three strategies for obtaining that goal were modeled. On the next level, these strategies were broken down into concrete goals and their corresponding strategies for the IT and sales departments of the business unit and the marketing group of the whole organization. On the third level, one IT-related strategy was broken down into the IT supplier (e.g., delivering software to the IT department), and the two marketingrelated strategies, which led to concrete goals and strategies for an external printing company (e.g., producing marketing material) and the IT department of the business unit (e.g., supporting the strategy with the IT).

$\mathrm{GQM}^{+}$Strategies ${ }^{\circledR}$ processes for creating and maintaining a model are based upon the Quality Improvement Paradigm [1] (QIP). Step 0 is preparatory and includes all the activities needed before starting the actual process (e.g., assigning resources and getting commitment). Steps 1-2 are related to grid generation and measurement definition, steps 3 and 4 are related to planning and executing the strategies, and steps 5 and 6 are related to analyzing the outcomes of strategic measurement programs:

1. Characterizing: Defining the scope for creating a model, characterizing the external and internal environment, i.e., the context to which the approach will be applied, and determining responsibilities for carrying out the approach.

2. Setting Goals: Developing the model structure, grid, measurement and interpretations based upon existing objectives within the defined scope, a gap analysis, interviews, and goal and strategy elicitation workshops.

3. Choosing Process: Planning the processes for implementing the strategies and collecting the data.

4. Executing Model: Applying the strategies, collecting the data, and starting to analyze the data to make adjustments, where necessary and possible in real time.

5. Analyzing Results: Interpreting the measurement results, assessing the success and failure of the strategies and the achievement of the goals. 
6. Packaging and Improving: Improving the model and measurement plan as well as reworking the goals and strategies over time.

The overall process defines a continuous improvement cycle. The defined goals and strategies are evaluated using the collected measurement data and decisions for improvement are made. These decisions result in removed, adapted, new goals and strategies, or extensions of the GQM ${ }^{+}$Strategies ${ }^{\circledR}$ grid.

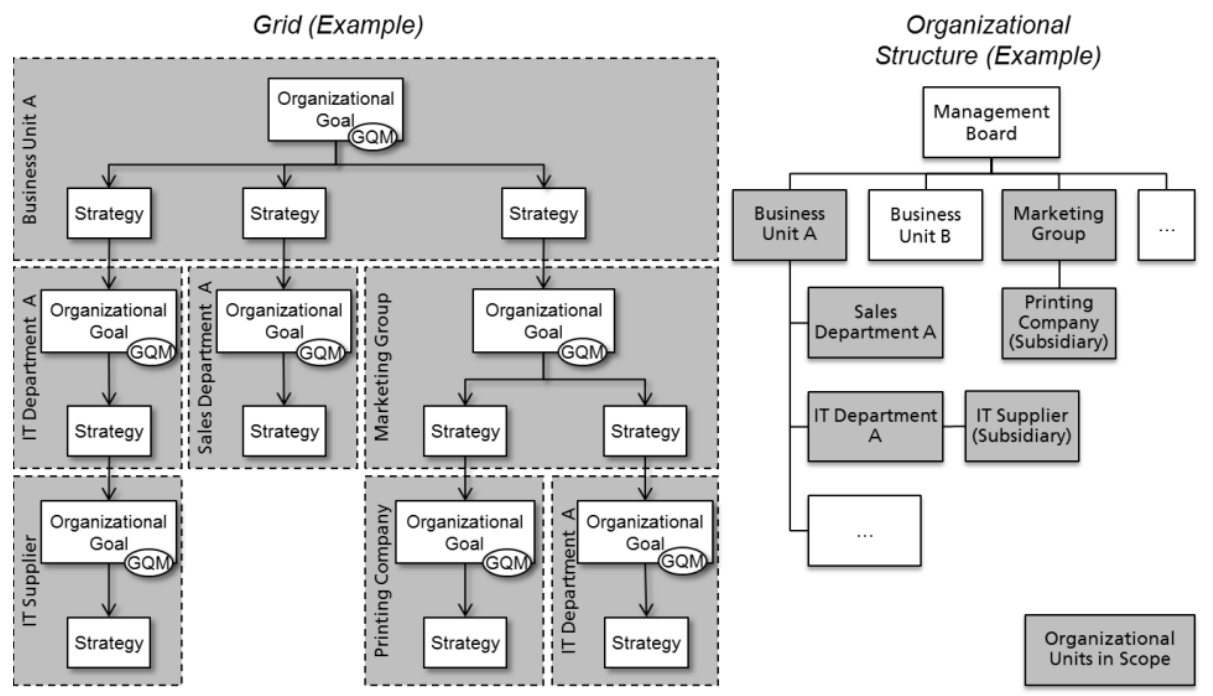

Fig. 2. Relationship between the $\mathrm{GQM}^{+}$Strategies ${ }^{\circledR}$ Grid and the Organizational Structure

\section{Business Alignment at ECOPETROL}

The following section gives an overview of the application of $\mathrm{GQM}^{+}$Strategies ${ }^{\circledR}$ in building a partial goal/strategy grid at ECOPETROL following the steps sketched above. The major activity applied and evaluated is the grid generation phase, so the emphasis is on the earlier steps in the process (characterize and set goals) and the effects of the grid development on the organization will be what is analyzed. The preparatory step 0 (initialize) is finished, i.e., initialization activities, such as planning and assigning resources and obtaining commitment, have taken place.

\subsection{Characterizing}

ECOPETROL is one of the top 50 oil and gas companies in the world and the largest company in Colombia. The IT function has roughly 140 employees and consists of several sub-groups addressing different IT-related tasks, including classical IT services as well as services related to information provision, software and system security, and Enterprise Architecture. A Software Factory (composed of external software 
development companies) is responsible for maintaining and integrating existing systems as well as for developing new IT-based software systems.

\subsection{Setting Goals and Measures}

In the context of evolving the department from a classical IT department to an information provider, the business value of the department and related activities had to be clarified and made measureable. This problem is not only specific to ECOPETROL but is generally an issue for many IT departments [5]. For this purpose, the $\mathrm{GQM}^{+}$Strategies ${ }^{\circledR}$ approach was applied to sub-functions of the IT department and an initial model was developed linking activities of the department to high-level goals. The reasons why ECOPETROL applied $\mathrm{GQM}^{+}$Strategies ${ }^{\circledR}$ were:

- To take whatever goals existed in the organization and formalize them by making them operational, i.e., specifying what is necessary to check whether the goal has been achieved;

- To generate an aligned, logical hierarchy of goals and strategies so that IT can know what it must do to support the needs of the top-level organization and that IT can demonstrate its value to the top-level organization (This involves filling in the blanks by identifying missing goals and strategies so that strategies can be checked to see whether they are achieving the goal they were selected to achieve.);

- To make all goals and strategies visible at all levels of the organization so that everyone is moving in the same direction;

- To define what should be measured and how it should be interpreted.

Workshops were conducted for eliciting goals, strategies, and existing measurement data in order to gain a common understanding. Mainly group and project leaders as well as SEPG (Software Engineering Process Group) people participated in those meetings. An initial gap analysis revealed that even though a set of high-level business-level goals (and corresponding strategies for implementing these goals) was available, it was hard to define the relationships among those goals and, most important, their impact on IT-level goals and activities. Fig. 3 shows excerpts from the initial GQM ${ }^{+}$Strategies ${ }^{\circledR}$ model. It focuses on connecting goals (G1 to G5) and strategies (S1 to S5) from the business level down to the IT level. It also documents the major rationales for linking the goals and strategies in terms of context factors (C1) and assumptions (A1 to A6). At the business level, three goals and corresponding strategies were defined, starting with the very high-level goal of being among the top 30 companies in terms of oil and gas reserves down to the lower-level goal (G3) of decreasing the analysis time for finding oil and gas reserves. At this stage, a strategy was defined to improve the quality of the information, because providing high-quality data will quickly support the decision-making process by decreasing the time needed to find new oil and gas reserves.

So, one central goal on the IT level is to improve and maintain information quality, which corresponds to strategy S3. Table 1 defines the goal for improving and maintaining information quality (G4) using the $\mathrm{GQM}^{+}$Strategies ${ }^{\circledR}$ goal template for 


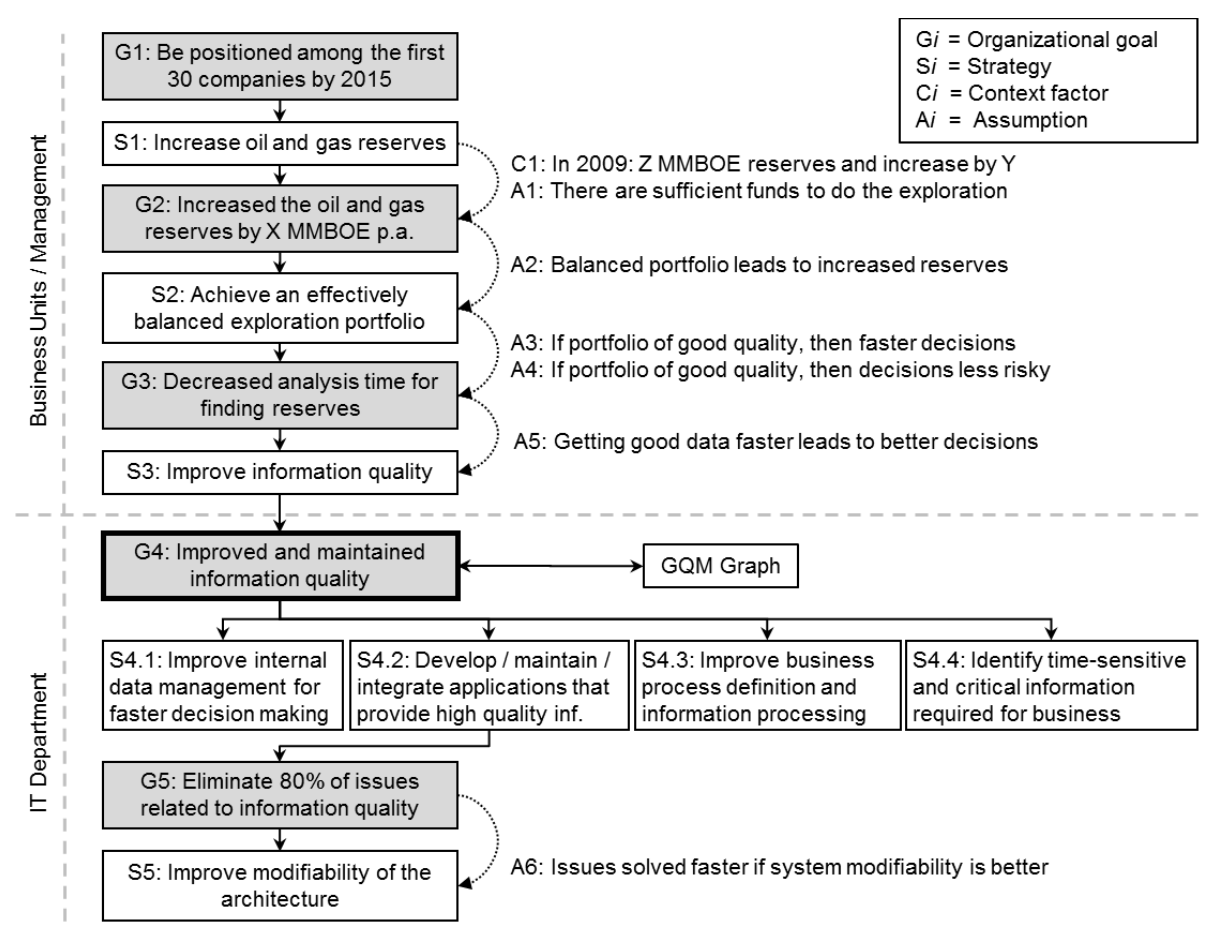

Fig. 3. Excerpt of the GQM ${ }^{+}$Strategies ${ }^{\circledR}$ Model

organizational goals. Information quality is broken down into five ECOPETROLspecific sub-concepts, which are representatives of common characteristics in the oil and gas industry [9] (Uniqueness, Completeness, Consistency, Timeliness, and Confidentiality). The IT department provides and manages several information units (pieces of critical information, such as information about wells or oil and gas reserves) for other ECOPETROL business units, covering the information needs of different business processes. The major goal on the IT level is to improve the quality of these information units by having $10 \%$ fewer critical information units (defined as status "red") and 10\% fewer medium-critical units (defined as status "yellow").

Although the model in Fig. 3 offers four different strategies addressing and operationalizing this goal, only one of them (S4.2) is shown as broken down to the level of improving the modifiability of the software architecture (S5). The others are not shown here.

The measurement goal here focuses on the achievement of the information quality improvement goal. For that purpose, GQM interviews were conducted with selected stakeholders from the IT department. As part of a first brainstorming session of these interviews, potential measurement goals related to information quality were identified. For each goal, a GQM abstraction sheet was defined. Table 2 gives an example abstraction sheet for analyzing the uniqueness of information units at ECOPETROL. 
Table 1. IT Organizational Goal "G4: Improved and maintained information quality"

\begin{tabular}{|l|l|}
\hline Focus & $\begin{array}{l}\text { Information quality (with attributes: Uniqueness, Completeness, Consis- } \\
\text { tency, Timeliness, and Confidentiality) }\end{array}$ \\
\hline Object & Information units of all business processes \\
\hline Magnitude & $\begin{array}{l}10 \% \text { decrease of \#reds for each attribute } \\
10 \% \text { decrease of \#yellows for each attribute }\end{array}$ \\
\hline Timeframe & Every 3 months \\
\hline Scope & $\begin{array}{l}\text { Information division for the upstream (related to exploration and produc- } \\
\text { tion of oil and gas reserves) }\end{array}$ \\
\hline Constraints & Use of resources for other activities \\
\hline Relations & Budget needs to be checked against revenue-related goals \\
\hline
\end{tabular}

A GQM abstraction sheet helps elicit and structure information during GQM interviews and assists in constructing, refining, and reviewing GQM goals, questions, and metrics. It consists of the GQM measurement goal and four quadrants.

During the planning phase, a prototype tool was used to store and access the grid. A spreadsheet was used for documenting all organizational goals, strategies, context factors, and assumptions, as well as the relationships among them. Based on that documentation, a simple tool generated visualizations of the specified structure, also enabling the user to browse through the different relationships.

Aligning and communicating all the goals, strategies, and measurement opportunities provides ECOPETROL with an integrated vision so that all elements of the organization can move in the same direction.

Based on the GQM ${ }^{+}$Strategies ${ }^{\circledR}$ model, an MS Excel-based questionnaire was developed for collecting data to analyze the achievement of the "improving and maintaining information quality" goal (Fig. 4). The questionnaire includes five different sections covering general information and the five attributes considered for information quality (uniqueness, completeness, consistency, timeliness, and confidentiality). The questionnaire was developed to ask representatives of both business and IT to provide their assessment of information quality. The opinions of both groups of representatives were critical, as some questions can only be answered if the knowledge and experience of business and IT come together.

Since it was critical to make the questionnaire understandable, and effective and efficient in gathering the appropriate information, it was piloted in a three-stage process. The first stage was conducted in a laboratory setting where influencing and environmental factors could be controlled (e.g., noise, distraction). During this stage, a sample group filled out the questionnaire in an artificial environment without disturbing influences. One purpose of this stage was to improve the understandability of the questionnaire based on the results of the laboratory study. During the second stage, the approach was piloted for a sample group that filled out the improved questionnaire in their real-life work setting. The results of this field study were used to analyze the information quality provided by individual business units and to do some final adaptation to the questionnaire before broadening the scope of users. 
During the third stage, the approach was applied in 13 different areas of the company (such as Financial, IT, Petrochemicals, and Communication). 86 information unit owners used the approach to assess 184 information units as part of interviews conducted together with measurement experts (Fig. 5). The experts supported the interviewees in answering the questions and collected feedback about the understandability and applicability of the questionnaire in practice. The average time needed for an interview was approx. 20 minutes. This time is expected to be reduced by at least $50 \%$ when the approach is fully rolled out.

Table 2. GQM Abstraction Sheet Excerpt

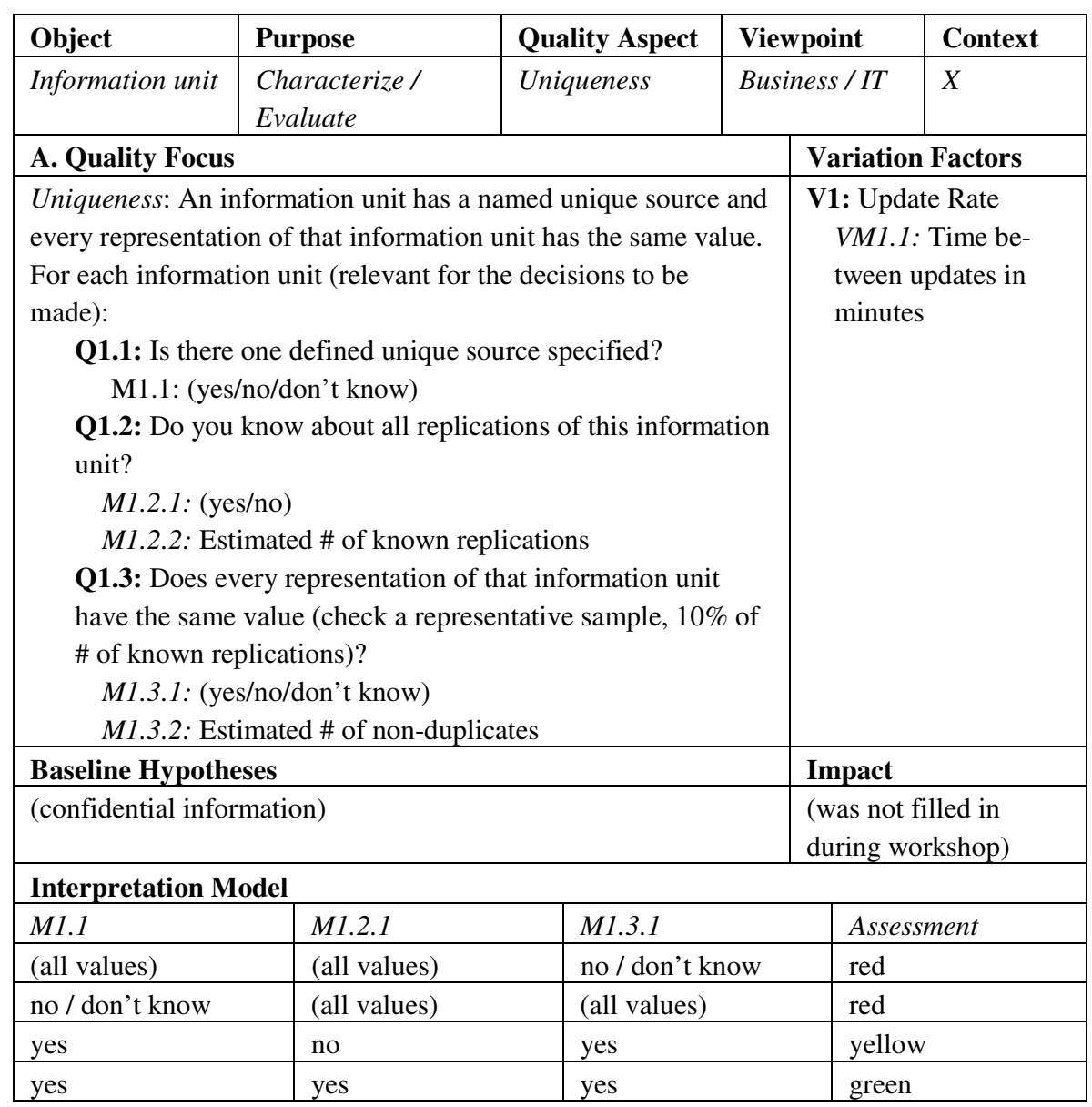




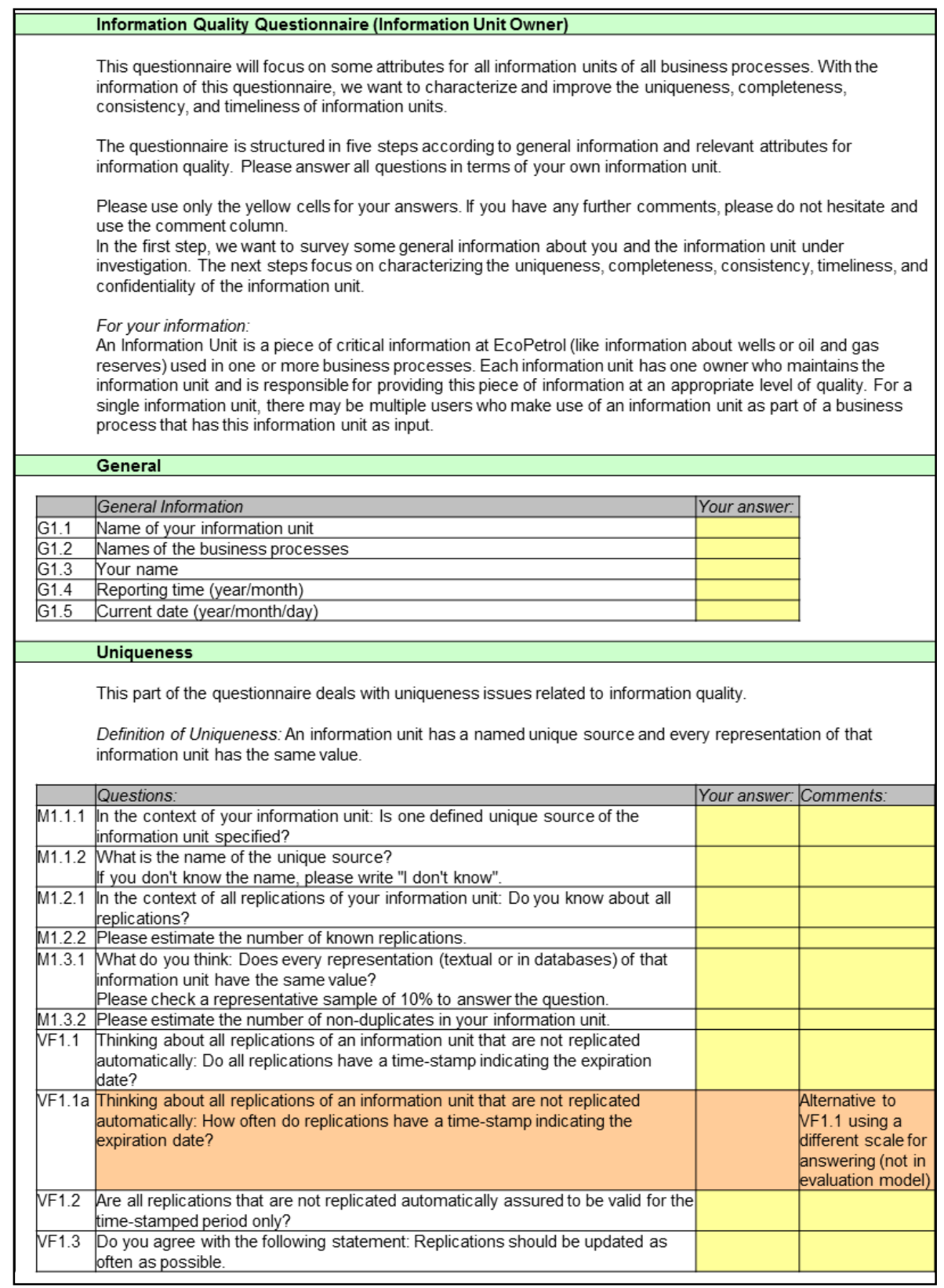

Fig. 4. Implementation of an IQ Questionnaire 


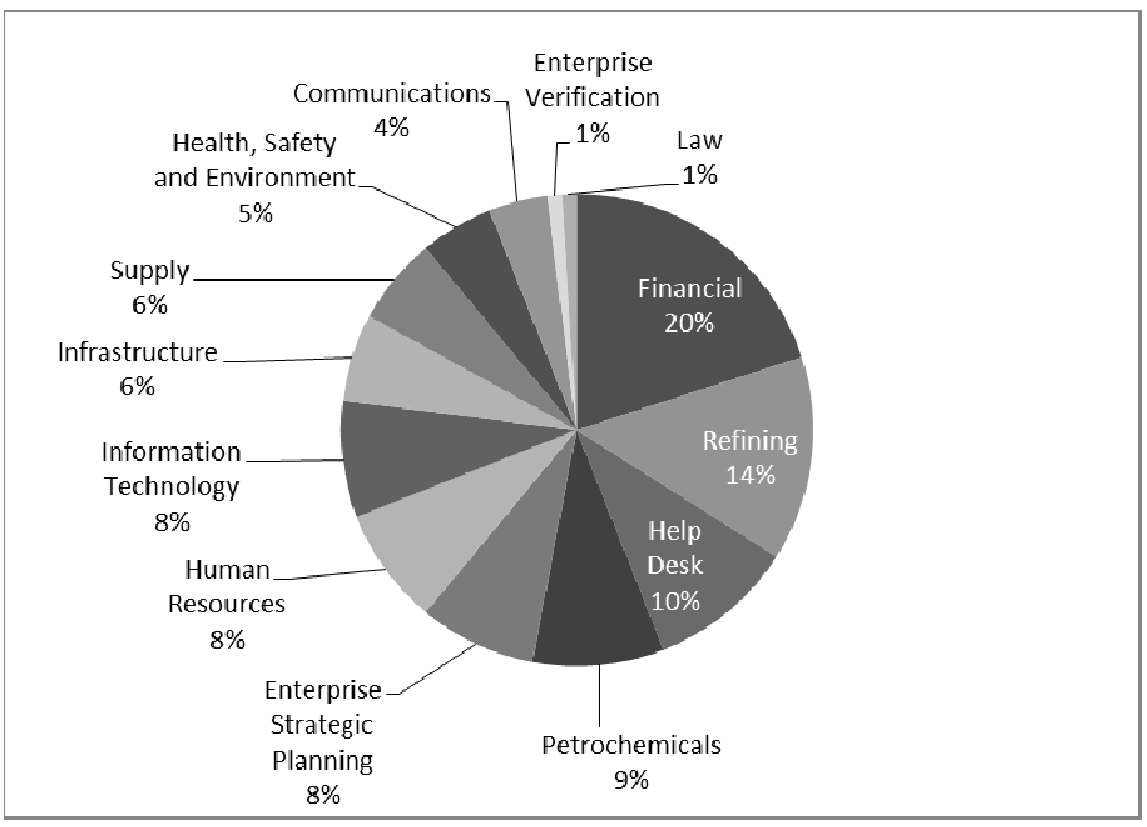

Fig. 5. Coverage of Business Areas

\section{$5 \quad$ An Initial Evaluation}

The evaluation of the application of the grid generation phase of $\mathrm{GQM}^{+}$Strategies ${ }^{\circledR}$ is an ongoing effort. Initial results are presented here.

First, an objective of the GQM+Strategies ${ }^{\circledR}$ developers was to assess how well the approach was communicated to the principal players at ECOPETROL so that they could apply the approach themselves. To this end, a form was used to evaluate the expertise of ECOPETROL personnel, which was filled out after the training and workshop sessions. The results of the evaluation support the belief that the training and workshops (two three-day sessions) provided sufficient expertise for ECOPETROL personnel to carry out the effort of grid development and implementation independently. More specifically, responders who participated in the tutorial and workshops said they understood the grid, could update and compare the strengths and weaknesses of variations in the grid, and could develop a grid for another part of the organization, but might want their results checked by an expert.

Second, the achievement of the specified Ecopetrol objectives was supported by the approach as seen by the example in this paper and the results of a second questionnaire. These objectives included: (1) taking existing implicit and explicit goals and formalizing them to make them operational, (2) generating an aligned, logical hierarchy of goals and strategies so that IT knows what it must do to support the needs of the top-level organization and can demonstrate its value to the top-level organization, (3) making all goals and strategies visible at all levels of the organization 
so that everyone is moving in the same direction, and (4) defining what should be measured and how it should be interpreted. The achievement of these objectives can be seen from the sample subset of goals in the paper as well as the responses to a second evaluation form, which revolved around assessing the benefits derived from the development of the grid. Both forms can be found at http://www.iese.fraunhofer.de/en/products/gqm/gqm_publications.html.

The resulting responses from both business and IT stakeholders were very positive. Both pointed out that it clarified their roles and goals, making it easy to see all the relationships (alignment) in order to communicate unambiguously with the business units (transparency). More specifically, the following comments were made by the evaluation participants, based upon interview questions:

- Was the process of building the grid helpful for your organization? "The grid really helped as a communication tool and a discovery tool, to gain more focus, and to explicitly link the goals of the organization with the IT organization."

- Is the resulting grid helpful for your organization? "Many of the IT services we're providing are not $100 \%$ represented in the grid. But we can show this grid to a business user and he/she can understand it quickly. [It is] really helpful for the IT organization because everyone should [think] about how his/her project supports the goals."

- What part of the grid is most helpful? "The explicit connections between the goals and the strategies."

- How has building the grid and the resulting grid impacted your way of thinking about your business and daily work? "The big cultural change we're [experiencing] right now is that you can use the grid to figure out where the new project should fit [in]."

- How well did the grid help you to quantify your organization's goals and strategies? "Before, we didn't have a measurement schema to deal with all the information. But the grid really helped us to define a formal way to ensure the quality of the data and the goals regarding what we want to do with the data."

The negative comments were related to tool support and the mental effort involved:

- The support tool for $\mathrm{GQM}^{+}$Strategies ${ }^{\circledR}$ is still a work in progress and is hard to use and not robust enough to deal with the full set of IT activities, much less the entire corporate grid; e.g., "We understand the methodology [and] can define and extend the grid. But we are not using the tool right now. The tool needs to be enhanced; especially the user interface." It should be noted that the tool used during this stage of the project has been replaced by a new tool with an interactive editor that allows specifying and browsing all elements of a $\mathrm{GQM}^{+}$Strategies ${ }^{\circledR}$ grid.

- The development of the grid requires the collaboration of several people representing different levels of the organization and is a non-trivial mental activity; e.g., "The people don't expect such intensive mental work [and] they should be prepared for that." 
Although the goal of this paper was to discuss and evaluate the results of the grid generation phase at ECOPETROL, one sign of success is that the questionnaire is currently being used as a measurement instrument by 72 information unit owners who are responsible for 808 information units. A tool that semi-automates the process and supports the information unit owners in completing the questionnaire has been developed and is being used [11]. This tool generates reports, which allow the information quality indicator to be calculated automatically. This information is being used in several ways, e.g., for building/updating the Ecopetrol IT roadmap and demonstrating the value of IT to the top-level organization. It can also be used as a baseline for new projects in the company's IT department, or as a basis for discussions on information governance.

Current data shows that measuring the quality of information units has helped some departments support their claims with empirical evidence and identify gaps such as the need for specific tool support for concrete activities, and it has helped identify highly effective processes and tools.

\section{Conclusions}

The application of $\mathrm{GQM}^{+}$Strategies ${ }^{\circledR}$ is a work in progress. There is evidence that the grid generation process seamlessly aligned the business at several levels of the organization. It has created a thread that links one major top level management goal down to the IT level, providing a rationale for each intermediate goal selection, and a means for assessing the success/failure of the collection of goals and strategies through measurement.

ECOPETROL continues to extend the model and collect and analyze data based upon the questionnaire. Data on information quality is being collected via various measurement instruments and is being used to assess the data. One extension already in progress is a measurement model for architectural maintainability, which is especially important on the level of integrating various IT projects. The planning and execution phase is now in progress and early indications are that the strategies are working well.

Current work on the $\mathrm{GQM}^{+}$Strategies $^{\circledR}$ approach is aimed at broadening the user base of the approach in order to gain more insights into the structure of goals and strategies, identifying common patterns that may be applicable in predefined environments, and creating an experience base of goals, strategies, and measurement data. Research activities include the integration of the work on Value-Based Software Engineering to deal with evaluating the ROI of various strategies [12].

Acknowledgments. We thank Jens Heidrich, Jürgen Münch, and Sabine Nunnenmacher for contributions to former versions of this paper, Vladimir Mandic for developing the evaluation forms and participating in the interviews, and Sonnhild Namingha for reviewing the article. 


\section{References}

1. Basili, V., Caldiera, G.: Improve software quality by reusing knowledge and experience. Sloan Management Review 37(1), 55-64 (1995)

2. Basili, V.R., Heidrich, J., Lindvall, M., Münch, J., Regardie, M., Rombach, D., Seaman, C., Trendowicz, A.: Linking software development and business strategy through measurement. IEEE Computer 43(4), 57-65 (2010)

3. Basili, V., Caldiera, G., Rombach, D.: Goal, question metric paradigm. Encyclopedia of Software Engineering, vol. 1, pp. 528-532. John Wiley and Sons (1994)

4. Carr, N.G.: IT doesn't matter. Harvard Business Review, 5-12 (May 2003)

5. CiGREF and Capgemini. Information: the next big challenge for business. White paper (December 2009)

6. Energy Intelligence. Petroleum Intelligence Weekly Newsletter (December 8, 2011)

7. ISACA, Control objectives for information and related technology (CoBIT®) (December 2007), http: / /www. isaca.org

8. Kaplan, R., Norton, D.: The balanced scorecard - measures that drive performance. Harvard Business Review 71 (January-February 1992)

9. Kozman, J., Ripley, T.: Sustainable spatial architecture for geo engineering data and workflows. In: Proceedings of the SPE Annual Technical Conference and Exhibition, Denver, Colorado, USA, September 21-24 (2008); paper no. SPE-116709.G

10. Lampasona, C., Heidrich, J., Basili, V., Ocampo, A.: Software quality modeling experiences at an oil company. In: ESEM 2012 Proceedings of the 2012 ACM-IEEE International Symposium on Empirical Software Engineering and Measurement, pp. 243-246 (2012)

11. Ocampo, A., Basili, V., Heidrich, J., Lampasona, C.: ECO-MAPS: An InformationCentered Approach for Enterprise Modeling. In: SATURN 2012: 8th SEI Architecture Technology User Network (SATURN) Conference (2012)

12. Mandic, V., Basili, V., Harjumaa, L., Oivo, M., Markkula, J.: Utilizing GQM+Strategies for business value analysis: an approach for evaluating business goals. In: Proceedings of the 2010 ACM-IEEE International Symposium on Empirical Software Engineering and Measurement (ESEM 2010), Article 20. ACM, New York (2010)

13. Marchand, D.A., Kettinger, W.J., Rollins, J.D.: Information orientation (IO): the link to business performance. Oxford University Press (2001)

14. Object Management Group (OMG), The business motivation model (BMM) v.1.1 (August 2010), http: / / www. omg . org

15. Office of Government Commerce (OGC). The IT infrastructure library (ITIL) service delivery, The Stationary Office London (2002)

16. US Department of Defense and US Army (DoD), Practical software and systems measurement: a foundation for objective project management, v.4.0c (March 2003), http: / /www.psmsc.com 